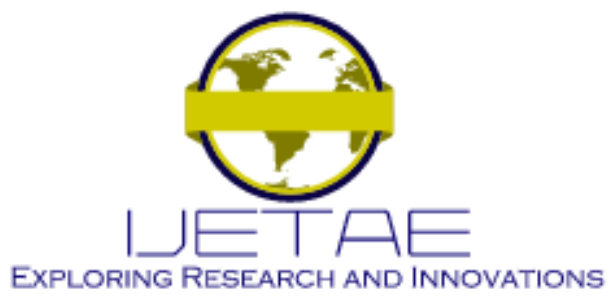

International Journal of Emerging Technology and Advanced Engineering

Website: www.ijetae.com (E-ISSN 2250-2459, Scopus Indexed, ISO 9001:2008 Certified Journal, Volume 11, Issue 11, November 2021)

Manuscript Received: 08 October 2021, Received in Revised form: 04 November 2021, Accepted: 10 November 2021

DOI: 10.46338/ijetae1121_20

\title{
Optimal Reactive Power Dispatch Using Multistage Artificial Immune System
}

\author{
Nur Farzana Nordin ${ }^{1}$, Mohd Helmi Mansor ${ }^{2}$, Karmila Kamil ${ }^{3}$, Nurzanariah Roslan ${ }^{4}$ \\ 1,2,3,4 Department of Electrical \& Electronics Engineering, College of Engineering, Universiti Tenaga Nasional, 43000 Kajang, \\ Selangor, Malaysia.
}

\begin{abstract}
Most countries over the past few decades have modernized their economies and become more reliant on electricity to run, so the electrical power system has also expanded greatly. Optimal Reactive Power Dispatch (ORPD) has a big influence on the reliability, security, and economic operation of the power system. Another thing to note is that ORPD has a few major targets and objectives which are to reduce the active or real power losses, to improve the voltage profile, to reduce transmission costs, and to increase system stability. Non-convex, non-linear, and multimodal problems make the development of intelligent algorithms to solve the reactive power dispatch problem highly relevant. Some researchers chose to compare and contrast optimization techniques from the past with each other in order to answer some remaining uncertainties such as the effectiveness and complexity of the technique toward the chosen objective function(s). Thus, this paper proposed applying the Multistage Artificial Immune System (MAIS) optimization method for solving the ORPD problem with the objective of reducing the power system losses. This algorithm was made by modifying and upgrading the classical AIS optimization method. Instead of only going through the process one time in the classical AIS algorithm, this MAIS method going through the processes more than one time in multiple stages of the same processes. This process includes cloning and mutation as well as selection. These modifications also aid in the development of new and unique solutions, as opposed to the classical AIS optimization process. Therefore, these enhancements could lead to a rise in the accuracy of the results\&\#39; because there have been increased comparisons. This study confirms that MAIS optimization can deliver superior results in less time than AIS.
\end{abstract}

Keywords-Optimal reactive power dispatch, computational intelligence, multistage artificial immune system, loss minimization.

\section{INTRODUCTION}

Active power and reactive power are the two components of complex power in an electrical power system.
The active power component flows from source to load and can perform useful work at the load; the reactive power component is caused by the delay between voltage and current, known as phase angle, and cannot perform useful work at the load. They each play an important role in the electrical power system. The system utilizes and makes use of the active power that has been drawn while the reactive power circulates in the system. In terms of voltage stability as well as active power transfer within the system, reactive power plays an important role [1]-[3]. In terms of generators, producing reactive power has a negative impact because it reduces the generator\&\#39;s ability to produce active power. As a result, reactive power resources had to be managed primarily so that power system operation could be secure and stable in terms of voltage stability [4]-[8].

Optimal Reactive Power Dispatch (ORPD) is a significant power system issue. The goal of solving the ORPD is to find the best operating point of the system for maximizing voltage stability, minimizing system loss, and minimizing voltage deviations. The best operating point includes the generator terminal voltages, transformer taps, and injected reactive powers of shunt compensators [9] . ORPD problem has a significant impact on both the secure and economic operation of power systems. Even though the generation of reactive power has no cost in production, it does affect the cost of overall generation in the connection of the transmission loss. A procedure that specifies the generation of reactive power to minimize transmission loss will result in the lowest cost of production while also meeting operational constraints. Nodal voltages, reactive power source capabilities, transformer tap position, and phase angles are examples of operational constraints [10], [11] . The optimal reactive power dispatch problem is thus set up. Furthermore, for decades, traditional gradient-based optimization algorithms have been widely used to solve this problem. This is a global optimization problem with multiple local minima, and conventional optimization methods easily lead to a local optimum. 


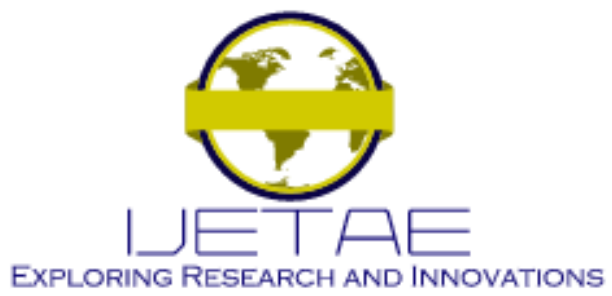

International Journal of Emerging Technology and Advanced Engineering Website: www.ijetae.com (E-ISSN 2250-2459, Scopus Indexed, ISO 9001:2008 Certified Journal, Volume 11, Issue 11, November 2021)

On the contrary, many mathematical assumptions, such as analytic and differential properties of objective functions, as well as unique minima in problem domains, must be provided in conventional optimization algorithms to simplify the problem. The gradient variables, on the other hand, are extremely difficult to calculate using conventional methods [12]-[14]. ORPD has a few major targets and objectives that most researchers are aware of, which are the minimization of the active or real power losses, theimprovement and development of the voltage profile, the transmission cost minimization and the stability voltage maximization in the power system [15]-[17] .

The increasing demand for reactive power loading in a power system has resulted in gradual voltage decay in line with the increase in transmission loss in the system. This has also caused stressed conditions in the system, making the system operate close to its point of collapse. The transmission loss can be minimized by performing reactive power planning which involves the optimization process [18], [19]. Therefore, some measures should be taken to support the reactive power loading and hence loss minimization could be effectively performed on the system. ORPD is crucial in power system operation in order for the power system to be economical and operate safely [20], [21]. ORPD is used to identify the optimal values of the reactive power dispatched by the generator for the purpose of minimizing the objective function considering the constraints, which is minimising the transmission loss [22]-[27] .

The Multistage Artificial Immune System (MAIS) method is proposed to solve the ORPD problem, aiming at power system losses minimization. This method is a new method where it is developed from the original Artificial Immune System (AIS) method, undergoing some modification. Instead of only having a single stage in AIS, MAIS has multiple stages of the same process of cloning, mutation and selection [28] . This study shall examine the optimum value of the reactive power needed to be dispatched by the generator to minimize the losses by using the MAIS method. This study is considered as a single objective optimization, which refers to optimizing one objective function at one time. The main objective of this study is to optimally dispatch reactive power via MAIS to minimize power system losses. This proposed algorithm was compared with the classical AIS optimization method with the purpose of validating its optimal performance in satisfying the objective function.
This study is limited to the reactive power dispatch by each generator in the power system, without considering transformer taps and generator terminal voltages.

\section{PROBLEM FORMULATION}

In order to solve the ORPD problem, the objective function considered in this optimization is to minimize power system losses. Equation (1) is used to calculate the losses.

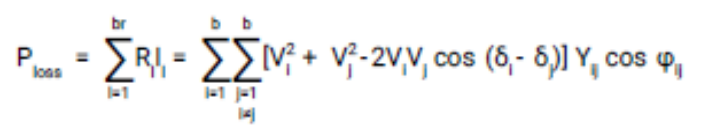

where:

$=$ the number of lines

$=$ the number of buses

$=$ the resistance of the line

$=$ the current that flow through the line

$=$ the voltage magnitude at node

$=$ the angle at node

$=$ the magnitude of the line admittance between bus and bus

$=$ the angle of the line admittance between bus and bus

The objective function is constrained by equality and inequality. The power balance constraint is the equality constraint. The power losses are equal to the difference between the generated power and the power demands. The equations of the power balance constraint for active and reactive powers can be represented by equation (2) and equation (3), respectively.

$$
\begin{aligned}
& P_{G i}-P_{D i}=V_{i} \sum_{j \in N_{i}} V_{j}\left(G_{i j} \cos \theta_{i j}+B_{i j} \sin \theta_{i j}\right) \\
& Q_{G i}-Q_{D i}=V_{i} \sum_{j \in N_{i}} V_{j}\left(B_{i j} \cos \theta_{i j}-G_{i j} \sin \theta_{i j}\right)
\end{aligned}
$$

where:

$V_{i}=$ the voltage at load bus

$V_{j}=$ the voltage at load bus

$B_{i j}=$ the susceptance between bus and bus

$G_{i}=$ the conductance between bus and bus

$P_{G i}=$ the generation of active power

$P_{D i}=$ the demand of active load

$Q_{G i}=$ the generation of reactive power

$Q_{D i}=$ the demand of reactive load 


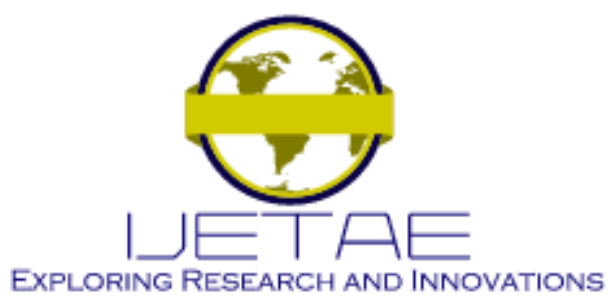

International Journal of Emerging Technology and Advanced Engineering

Website: www.ijetae.com (E-ISSN 2250-2459, Scopus Indexed, ISO 9001:2008 Certified Journal, Volume 11, Issue 11, November 2021)

Meanwhile, the generator operating limits, transformer tap setting, and reactive power compensator sizing are the inequality constraints. For the generator operating limits, the voltage of the bus generator, as well as the reactive power and active power output generations, are restricted and bounded by their limits and boundaries, as shown in equations (4), (5) and (6).

$$
\begin{array}{cc}
\mathrm{P}_{\mathrm{G}, \text { min }} \leq \mathrm{P}_{\mathrm{Gi}} \leq \mathrm{P}_{\mathrm{Gl}, \max } & \mathrm{i}=1,2,3, \ldots \mathrm{N}_{\mathrm{G}} \\
\mathrm{Q}_{\mathrm{Gi}, \min } \leq \mathrm{Q}_{\mathrm{Gi}} \leq \mathrm{Q}_{\mathrm{Gl}, \max } & \mathrm{i}=1,2,3, \ldots \mathrm{N}_{\mathrm{G}} \\
\mathrm{V}_{\mathrm{Gi}, \min } \leq \mathrm{V}_{\mathrm{Gi}} \leq \mathrm{V}_{\mathrm{Gl}, \max } & \mathrm{i}=1,2,3, \ldots \mathrm{N}_{\mathrm{G}}
\end{array}
$$

where:

$\mathrm{P}_{\mathrm{Gi} \text { min }}=$ the lower limit of outputs generations of The active power

$\mathrm{P}_{\mathrm{Gi}, \max }=$ the upper limit of outputs generations Of the active power

$\mathrm{Q}_{\mathrm{Gi} \text {,min }}=$ the lower limit of outputs generations of The reactive power

$\mathrm{Q}_{\mathrm{Gi}, \max }=$ the upper limit of outputs generations of the reactive power

$\mathrm{V}_{\mathrm{Gi} \text {,min }}=$ the lower limit of the voltages of the Bus generator

$\mathrm{V}_{\mathrm{Gi} \text { max }}=$ the upper limit of the voltages of the Bus generator

$\mathrm{N}_{\mathrm{G}}=$ the number of the generators

For the second in equality constraint, which is the Transformer tap setting, the tap setting value is Restricted and bounded by its limits and boundaries, Which is as follows:

$$
T_{i, \min } \leq T_{i} \leq T_{i, \max } \quad i=1,2,3, \ldots N_{T}
$$

where:

$\mathrm{T}_{\mathrm{i}, \mathrm{min}}=$ the lower limit of the constraints of the Transformer tap setting

$\mathrm{T}_{\mathrm{i}, \max }=$ the upper limit of the constraints of the Transformer tap setting

$\mathrm{N}_{\mathrm{T}}=$ the number of the transformers

Lastly, for there active power compensator sizing constraint, it is ensured that the size of the compensator is with in the allow able limits as shown in equation (8).

$$
\mathrm{Q}_{\mathrm{Cl}, \min } \leq \mathrm{Q}_{\mathrm{Cl}} \leq \mathrm{Q}_{\mathrm{Cl}, \max } \mathrm{i}=1,2,3, \ldots \mathrm{N}_{\mathrm{C}}
$$

where:

$\mathrm{Q}_{\mathrm{Ci} \text { min }}=$ the lower limit of the constraints of the

Sizing of the reactive compensators

$\mathrm{Q}_{\mathrm{Ci} \text { max }}=$ the upper limit of the constraints of the

Sizing of the reactive compensators

$\mathrm{N}_{\mathrm{C}}=$ the number of the reactive compensators

\section{MAIS FOR ORPD}

The MAIS optimization method is used to solve the ORPD problem. This algorithm is one of the new optimization methods that arose from changes and enhancements to the traditional AIS optimization method. Figure 1 depicts the flow of the proposed algorithm.

The following steps explain the processes of MAIS to implement it in the optimization of ORPD with the goal of minimizing power system losses:

Step 1:

The first step is to generate a random set of control variables for active and reactive powers. Equation (1) and equation (2) demonstrate the formulas for generating random numbers for active and reactive powers, respectively.

$$
\begin{aligned}
& P_{i}=\operatorname{rand}(a, b) \times P_{\text {off_set }}+P_{\text {min_set }} \\
& Q_{i}=\operatorname{rand}(a, b) \times Q_{\text {off_set }}+Q_{\text {min_set }}
\end{aligned}
$$

where:

$\mathrm{P}_{\mathrm{i}}=1,2,3,4$ and 5

$\mathrm{Q}_{\mathrm{i}}=1,2,3,4$ and 5

$\mathrm{a}=$ the number of row

$\mathrm{b}=$ the number of column

$\mathrm{P}_{\text {off_set }}=$ the maximum of the generator active Power limit

$\mathrm{P}_{\text {min_set }}=$ the minimum of the generator active Power limit

$\mathrm{Q}_{\text {off_set }}=$ the maximum of the generator reactive Power limit

$\mathrm{Q}_{\text {min_set }}=$ the minimum of the generator reactive Power limit

The variables denoted as $\mathrm{P}_{1}, \mathrm{P}_{2}, \mathrm{P}_{3}, \mathrm{P}_{4}$ and $\mathrm{P}_{5}$ represent the active power of the generator at busses $2,5,8,11$, and 13. The same is true for reactive power, where $Q_{1}, Q_{2}, Q_{3}$, $\mathrm{Q}_{4}$ and $\mathrm{Q}_{5}$ represent the reactive power of the generator at buses $2,5,8,11$, and 13 . To ensure that the generated random numbers satisfy the problem constraints, equation (2) and equation (3) are used in their generation. 


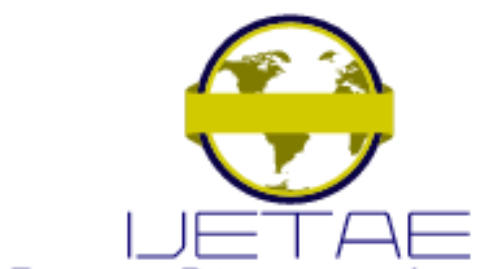

EXPLORING RESEARCH AND INNOVATIONS

International Journal of Emerging Technology and Advanced Engineering

Website: www.ijetae.com (E-ISSN 2250-2459, Scopus Indexed, ISO 9001:2008 Certified Journal, Volume 11, Issue 11, November 2021)

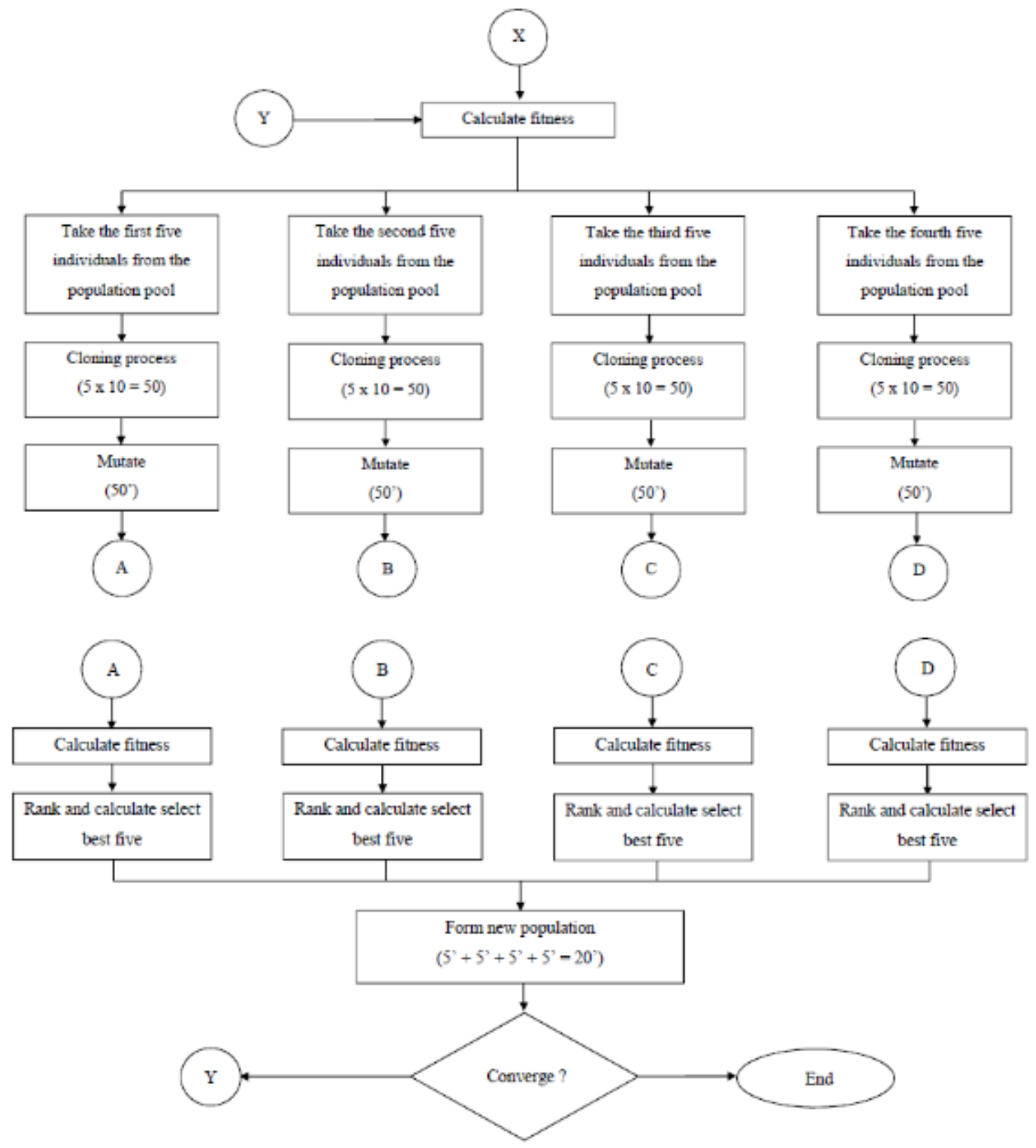

Figure 1. MAIS flow chart 


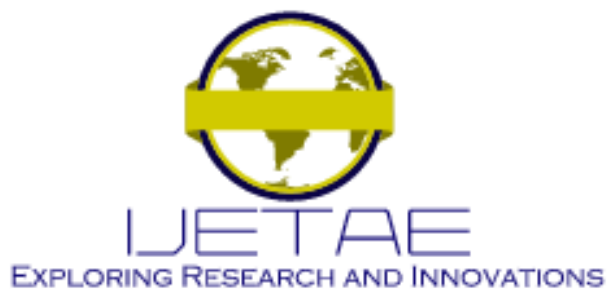

International Journal of Emerging Technology and Advanced Engineering

Website: www.ijetae.com (E-ISSN 2250-2459, Scopus Indexed, ISO 9001:2008 Certified Journal, Volume 11, Issue 11, November 2021)

Step 2:

The generated random numbers would then be subjected to the fitness calculation process in this step. Because MAIS is used to solve a minimization problem in this paper, the fitness is the inverse of the objective function. As a result, the fitness value calculated for each random number would be the power system losses. The calculated power system losses must be less than the base losses discovered by running the power system\&\#39;s load flow as shown in (11). These generated random numbers of control variables, also known as individuals, are generated until a total of 20 random numbers or individuals are generated, based on the fitness being calculated.

\section{system_losses $\leq$ base_losses}

Step 3:

The generated random numbers that satisfied the calculated fitness condition would then fill up the population pool in this step.

Step 4:

The generated random number would then go through the process of calculating fitness for the second time in this step.

Step 5:

As a result, in this step, the initial population, which consists of 20 individuals, is grouped and classified into four sub-groups or sub-populations. Each sub-population has five members. Then, each sub-population would go through the cloning, mutation, and selection processes separately.

Step 6:

Following that, each sub-population would go through the cloning process. This cloning process can be expressed using MATLAB programming code as follows:

$$
\text { Clone_k }=\operatorname{repmat}(\mathrm{A},[\mathrm{i}, \mathrm{j}])
$$

where:

$\mathrm{k}=$ the stage number

$\mathrm{A}=$ the subject to clone

$\mathrm{i}=$ clone the row

$\mathrm{j}=$ clone the column
The cloning process is carried out by cloning each individual ten times. As a result, the population for each sub-population would be 50 .

Step 7:

Following that, in this step, each sub-population would go through the mutation process, employing the Gaussian Mutation technique to produce offspring. This Gaussian Mutation technique\&\#39;s equation is shown in equation (13).

$$
x_{i+m, j}=x_{i j}+N\left(0, \beta\left(x_{i, \max }-x_{j, \min }\right)\left(\frac{f_{i}}{f_{\max }}\right)\right)
$$

where:

$\mathrm{x}_{\mathrm{i}+\mathrm{m}, \mathrm{j}}=$ the mutated parent also known as off spring $\mathrm{x}_{\mathrm{i}, \mathrm{j}}=$ parents

$\mathrm{N}=$ Gaussian random variable with mean $\mu$ and variance $\gamma 2$ $\beta=$ the mutation scale, $0<\beta<1$

$\mathrm{x}_{\mathrm{j}, \max }=$ the maximum random number for every variable $\mathrm{x}_{\mathrm{j}, \mathrm{min}}=$ the minimum random number for every variable $\mathrm{f}_{\mathrm{i}}=$ the fitness for the $\mathrm{i}^{\text {th }}$ random number $\mathrm{f}_{\max }=$ the maximum fitness

Step 8:

Subsequently, the offspring would go through the process of calculating fitness for the third time in this step, which would be the power system losses.

Step 9:

The offspring that went through the process of calculating fitness would be ranked in this step, and the top five of each sub-population would be chosen.

Step 10:

Then, in this step, the top five sub-populations would be combined to form a new population of 20 individuals.

Step 11:

Finally, the new population would go through the convergence test to find the local optima. If the convergence test is met, the output of the optimal solution, which is the highest fitness value obtained thus far, is returned, and the MAIS algorithm is terminated. If, on the other hand, the convergence test condition was not met, the algorithm would restart from step 4. 


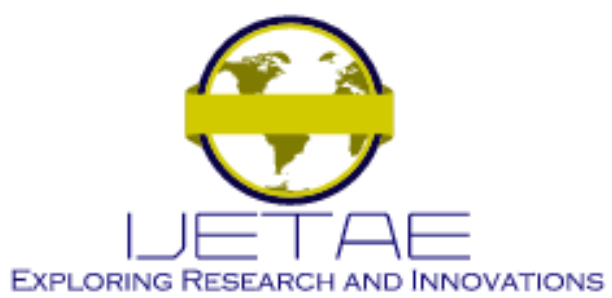

International Journal of Emerging Technology and Advanced Engineering

Website: www.ijetae.com (E-ISSN 2250-2459, Scopus Indexed, ISO 9001:2008 Certified Journal, Volume 11, Issue 11, November 2021)

\section{RESUlts AND Discussion}

The MAIS-solved ORPD problem was tested on the IEEE 30-bus Reliability Test System (RTS) with the goal of minimizing power system losses. This test system has 24 load buses, 6 generator buses, and a slack bus, with a total of 41 interconnected lines. The system has five active power generators and four transformer tap positions that are considered control variables, with the system\&\#39;s base MVA of 100MVA. Figure 2 depicts a one-line diagram of the system. In addition, a brief description of this test system is provided in Table I. The MAIS algorithm was written and executed in the MATLAB R2020a software. It was run on a computer with Windows 10, a core i5 processor, and 8GB of Random-Access Memory (RAM).

TABLE I

SHORT DESCRIPTION OF THE IEEE30- BUS RTS

\begin{tabular}{lll}
\hline No. & Item & Description \\
\hline 1. & Buses & 30 \\
2. & Lines & 41 \\
3. & Gencrators & 6 \\
4. & Tap transformers & 4 \\
5. & Shunt capacitors & 9 \\
6. & Load buses & 24 \\
7. & P load (MW) & 283.40 \\
8. & Q load (MVAR) & 126.20 \\
9. & P. (MW) & 289.211 \\
10. & Qm (MVAR) & 108.922 \\
11. & Initial P loss (MW) & 5.812 \\
12. & Initial Q loss (MVAR) & 32.417 \\
\hline
\end{tabular}

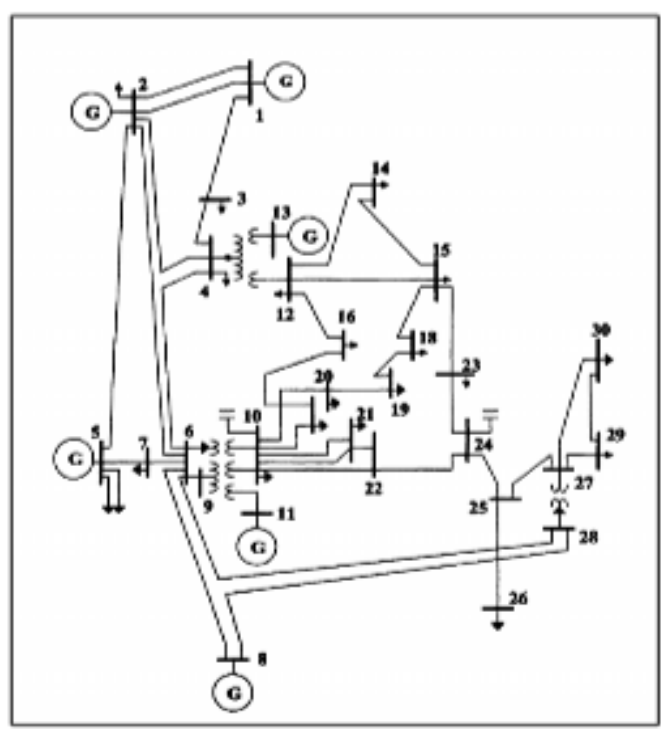

Figure2. IEEE30-Bus RTS
There are three case studies introduced in solving ORPD using MAIS to ensure that MAIS is powerful enough in comparison to AIS. Case 1 is the first case, also known as the base case. The base case is where the optimization is performed with no changes to the load of the IEEE 30-Bus RTS. Case 2, also known as the loading condition. In this case, bus 3 is chosen for this type of case because it is subjected to a range of loads ranging from 50 MVAR to 200 MVAR. The total of power system losses recorded as the loading condition gradually increases. Case 3, also known as the N-1 line contingency. In this case, an IEEE 30-Bus RTS line is excluded during the optimization process. Lines 1-2 and 2-5 were chosen because they have a high value in power losses. During the optimization process, however, these two-line data are excluded one at a time.

To validate the performance of the MAIS method, it was compared with the AIS optimization method; thus, this AIS optimization method was also used to solve the ORPD problem. As a result, based on the three case studies, both algorithms were tested on the IEEE 30-Bus RTS to determine power system losses as well as the computational time of each optimization method. The tabulation data of the results of optimization using the AIS optimization method is shown in Table II. Furthermore, Table III shows the tabulation data of the results of the MAIS optimization method. Furthermore, Table IV compares the results of optimization using both algorithms.

According to Table II, the generator at bus 2 absorbed 8.41 MVAR of reactive power, while the generators at buses $5,8,11$, and 13 supplied reactive power to the system for Case 1 and most of Case 2. There are, however, two exceptional circumstances. When the reactive load of the generator at bus 3 increased by 200 MVAR, the generator at bus 11 absorbed the system\&\#39; reactive power, which is $3.82 \mathrm{MVAR}$, instead of the generator at bus 2 , while the other generators at bus $5,8,11$, and 13 supplied the system\&\#39;s reactive power, which is between 12.95 MVAR and 3.82 MVAR. When line1-2 of Case 3 is excluded from the optimization process, the generator at bus 5 absorbs the system\&\#39;s reactive power, which is $14.48 \mathrm{MVAR}$, while the other generators at bus $2,8,11$, and 13 supply the system\&\#39;s reactive power, which ranges between $1.98 \mathrm{MVAR}$ and 59.06 MVAR. 


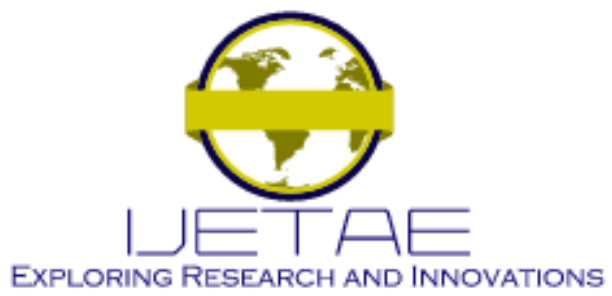

International Journal of Emerging Technology and Advanced Engineering Website: www.ijetae.com (E-ISSN 2250-2459, Scopus Indexed, ISO 9001:2008 Certified Journal, Volume 11, Issue 11, November 2021)

Based on Table III, it is clear for Case 1 and most of Case 2 that the generator at bus 2 absorbed reactive power ranging from 7.39 MVAR to 11.88 MVAR, despite the fact that the other generators at bus 5, 8, 11, and 13 supplied reactive power to the system. On the other hand, there are two exceptions. When the reactive load of the generator at bus 3 increased by $200 \mathrm{MVAR}$, the generator at bus 11 absorbed the system\&\#39;s reactive power, which is 8.82 MVAR, while the other generators at bus 2, 5, 8, and 13 supplied the reactive power to the system, which is in the range of 9.95 MVAR to 22.55 MVAR. Meanwhile, in Case 3 , where the line 1-2 data is excluded during the optimization process, the generator at bus 5 absorbed the system\&\#39;s reactive power, which is 17.45 MVAR, while the other generators at bus 2, 8, 11, and 13 supplied the system\&\#39;s reactive power, which is between 2.44 MVAR and 58.60 MVAR.

In Cases 2 and 3, the MAIS optimization method achieved lower power system losses than the AIS optimization method, as shown in Table IV. In Case 2, for example, when the reactive load of the generator at bus 3 is increased by $125 \mathrm{MVAR}$, the losses for the MAIS optimization method are less than those for the AIS optimization method, which are 8.50 MW. In addition, when the reactive load of the generator at bus 3 is increased by 200 MVAR, the losses found using the MAIS optimization method are lower than the losses found using the AIS optimization method, which is 14.92 MW. MAIS, on the other hand, produced the same results as AIS in the base case. It can also be seen that the computation time of MAIS is nearly half that of AIS. These results demonstrate that not only can the MAIS optimization method produce better results, but it can also produce results in a short amount of time. This MAIS optimization method goes through the processes multiple times in different stages of the same process. Cloning, mutation, and selection are examples of these processes. Because the number of comparisons has increased, these modifications can generate a broader and wider range of possible solutions, which can aid in the increase in the accuracy of the production of results.

\section{CONCLUSION}

This paper successfully presented the use of Multistage Artificial Immune System (MAIS) to solve the Optimal Reactive Power Problem (ORPD).
Three case studies were introduced to solve the ORPD problem: Case 1 (base case), Case 2 (loading condition), and Case 3 (N-1 line contingency). The optimization results obtained with MAIS were compared to the optimization results obtained with AIS. According to the findings, MAIS not only produced better ORPD results in terms of low power system losses, but this optimization method can also produce results in a relatively short period of time. This could be because the MAIS optimization method goes through the processes multiple times in multiple stages of the same processes. Cloning, mutation, and selection are examples of these processes. Because the number of comparisons has increased, these modifications can generate a broader and wider range of possible solutions, which can aid in the increase in the accuracy of the production of results.

\section{Acknowledgement}

The authors would like to thank the Innovation and Research Management Centre (iRMC), Universiti Tenaga Nasional (UNITEN) for funding this research. UNITEN has fully funded this research through the Bold Publication Fund, with the code J510050002.

\section{REFERENCES}

[1] C. Dai, W. Chen, Y. Zhu, and X. Zhang, "Seeker optimization algorithm for optimal reactive power dispatch," IEEE Trans. Power Syst., vol. 24, no. 3, pp. 1218-1231, 2009.

[2] M. Ettappan, V. Vimala, S. Ramesh, and V. T. Kesavan, "Optimal reactive power dispatch for real power loss minimization and voltage stability enhancement using Artificial Bee Colony Algorithm," Microprocess. Microsyst., vol. 76, p. 103085, 2020.

[3] M. S. Saddique et al., "Solution to optimal reactive power dispatch in transmission system using meta-heuristic techniques-Status and technological review," Electr. Power Syst. Res., vol. 178, no. August 2019, p. 106031, 2020.

[4] H. P. Singh, Y. S. Brar, and D. P. Kothari, "Active and reactive power dispatch using predator prey optimization approach," India Int. Conf. Power Electron. IICPE, vol. 2016-Novem, no. 1, 2016.

[5] M. Mehdinejad, B. Mohammadi-Ivatloo, R. Dadashzadeh-Bonab, and K. Zare, "Solution of optimal reactive power dispatch of power systems using hybrid particle swarm optimization and imperialist competitive algorithms," Int. J. Electr. Power Energy Syst., vol. 83, pp. 104-116, 2016.

[6] V. J. Gumera-Toque and A. C. Nerves, "Optimization of generator Reactive Power Dispatch in restructured power systems," IEEE Reg. 10 Annu. Int. Conf. Proceedings/TENCON, vol. 2016-Janua, pp. 610, 2016.

[7] A. H. Khazali and M. Kalantar, "Optimal reactive power dispatch based on harmony search algorithm," Int. J. Electr. Power Energy Syst., vol. 33, no. 3, pp. 684-692, 2011. 


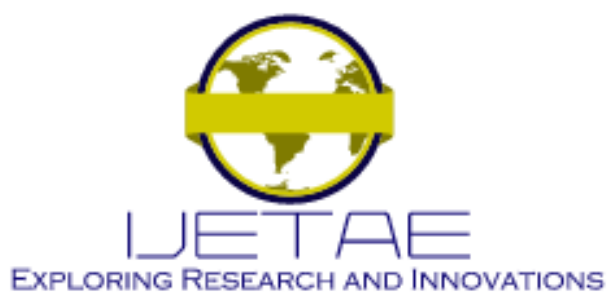

International Journal of Emerging Technology and Advanced Engineering

Website: www.ijetae.com (E-ISSN 2250-2459, Scopus Indexed, ISO 9001:2008 Certified Journal, Volume 11, Issue 11, November 2021)

[8] Q. Li, Q. Cao, and Y. Zhang, "Robust Optimal Reactive Power Dispatch against Line Parameters Uncertainty," 2018 Int. Conf. Power Syst. Technol. POWERCON 2018 - Proc., pp. 3729-3733, 2019.

[9] M. Ebeed, A. Alhejji, S. Kamel, and F. Jurado, "Solving the optimal reactive power dispatch using marine predators algorithm considering the uncertainties in load and wind-solar generation systems," Energies, vol. 13, no. 17, 2020.

[10] S. Feng, Y. Licheng, G. Zhitong, and C. Yanhong, "Reactive power optimization compensation of line losses calculation in rural areas," in Proceedings of the 30th Chinese Control and Decision Conference, CCDC 2018, 2018, pp. 6458-6463.

[11] K. R. C. Mamandur and R. D. Chenoweth, "Optimal Control of Reactive Power Flow for Improvements in Voltage Profiles and for Real Performance of Third Harmonic Ground Fault Protection Schemes for Generator Stator Windings Consolidated Edison Dispatcher Simulator Training at," IEEE Power Eng. Rev., vol. PER- 1, no. July, pp. 29-30, 1981.

[12] N. B. Roy and D. Das, "Optimal allocation of active and reactive power of dispatchable distributed generators in a droop controlled islanded microgrid considering renewable generation and load demand uncertainties," Sustain. Energy, Grids Networks, vol. 27, p. 100482, 2021.

[13] R. Ng Shin Mei, M. H. Sulaiman, Z. Mustaffa, and H. Daniyal, "Optimal reactive power dispatch solution by loss minimization using moth-flame optimization technique," Appl. Soft Comput. J., vol. 59, pp. 210-222, 2017.

[14] S. Mouassa, T. Bouktir, and A. Salhi, "Ant lion optimizer for solving optimal reactive power dispatch problem in power systems," Eng. Sci. Technol. an Int. J., vol. 20, no. 3, pp. 885-895, 2017.

[15] A. Abaza, A. Fawzy, R. A. El-Sehiemy, A. S. Alghamdi, and S. Kamel, "Sensitive reactive power dispatch solution accomplished with renewable energy allocation using an enhanced coyote optimization algorithm," Ain Shams Eng. J., vol. 12, no. 2, pp. 1723-1739, 2021.

[16] S. Raha, T. Som, and N. Chakraborty, "Constriction factor based particle swarm optimization applied to reactive power dispatch in transmission system," IET Conf. Publ., vol. 2011, no. 583 CP, pp. 335-339, 2011.
[17] W. Ongsakul and D. Vo Ngoc, Artificial Intelligence in Power System Optimization. CRC Press, 2013.

[18] P. P. Biswas, P. N. Suganthan, R. Mallipeddi, and G. A. J. Amaratunga, "Optimal reactive power dispatch with uncertainties in load demand and renewable energy sources adopting scenario-based approach," Appl. Soft Comput. J., vol. 75, pp. 616-632, 2019.

[19] Q. H. Wu, Y. J. Cao, and J. Y. Wen, "Optimal reactive power dispatch using an adaptive genetic algorithm," Int. J. Electr. Power Energy Syst., vol. 20, no. 8, pp. 563-569, 1998.

[20] J. D. Glover, M. S. Sarma, and T. Overbye, Power Systems Analysis and Design 5th Edition. Cengage Learning, 2011.

[21] N. Wang et al., "Optimal active and reactive power cooperative dispatch strategy of wind farm considering levelised production cost minimisation," Renew. Energy, vol. 148, pp. 113-123, 2020.

[22] B. Bhattacharyya and S. Kumar, "Reactive power planning with FACTS devices using gravitational search algorithm," Ain Shams Eng. J., vol. 6, no. 3, pp. 865-871, 2015.

[23] Y. M. Zhang, C. R. Chen, and C. Y. Lee, "Solution of the optimal reactive power dispatch for power systems by using novel charged system search algorithm," Proc. - 2018 7th Int. Symp. NextGeneration Electron. ISNE 2018, no. Isne, pp. 1-4, 2018.

[24] L. Yan, T. Xinshou, H. Jianzu, and L. Chao, "Research on Reactive Power Planning Technology of Power Grid Containing UHVDC System with High Proportion of Renewable Energy Integration," $7^{\text {th }}$ IEEE Int. Conf. High Volt. Eng. Appl. ICHVE 2020 - Proc., pp. 1-4, 2020.

[25] A. B. Birchfield, T. Xu, and T. J. Overbye, "Power flow convergence and reactive power planning in the creation of large synthetic grids," IEEE Trans. Power Syst., vol. 33, no. 6, pp. 66676674, 2018.

[26] M. Khalid, "Short-Term Reactive Power Planning to Minimize Cost of Energy Losses Considering PV Systems," IEEE Trans. Smart Grid, vol. 11, no. 2, p. 1812, 2020.

[27] S. Mugemanyi, Z. Qu, F. X. Rugema, Y. Dong, C. Bananeza, and L. Wang, "Optimal Reactive Power Dispatch Using Chaotic Bat Algorithm," IEEE Access, vol. 8, pp. 65830-65867, 2020.

[28] S. C. Mohd Nasir et al., "Multistage artificial immune system for static VAR compensator planning," Indones. J. Electr. Eng. Comput. Sci., vol. 14, pp. 346-352, 2019. 